\title{
Nanjing Library's Reference Service Yesterday, Today and Tomorrow
}

\author{
Wang Bing \\ Deputy Director of Nanjing Library, Jiangsu, China
}

\begin{abstract}
This paper systematically reviews the history of Nanjing Library reference service as well as its achievements today. It traces Nanjing Library's development from its predecessor Jiangnan Library, National Central Library to Nanjing Library, and examines each stage from three perspectives: 1) book collection; 2) service measures and bibliography writings; and 3 ) consulting service cases and senior experts. It also anticipates Nanjing Library's reference service in the next 3 to 5 years, observing four trends of development: 1) domestic and foreign cooperation, 2) service for party and government organizations, 3) service for scientific research and production, and 4) new technology and new media application.
\end{abstract}

Keywords: Nanjing Library, Jiangnan Library, National Central Library, History of reference service, Joint Reference Network of Jiangsu Public Library, Legislation decision-making information service

\section{INTRODUCTION}

In 1895, the Chinese bourgeois reformists, Kang Youwei's "Letter to the Qing Emperor about Opening the Palace to Widely Display Book" is generally regarded as the earliest appeal about Chinese modern library reference work (Li, 1982: 88-89). From now on, China library's reference service went into its infancy. Zan Dermo, professor of Wuhan University believes that in the 20th century, the development of Chinese library reference were experienced its embryonic period (from the end of the 19th century to the early 20th century), formative period (from the eve of the 1920s to the 30s), renaissance period (1950s), flourish period (from the late 1970s to the 80s), improving period (1990s). (Zhan, 2000: 1-7, 28) It turned out that Nanjing library's reference service, from its predecessors, the Jiangnan Library (constructed in 1907) and the National Central Library (constructed in 1933), experienced the each period in one hundred years of trials, hardships and upside down, and got great development in the 21st century. However, now we still can't help moving! We can confidently say: the history of Nanjing Library's reference work has become a microcosm and an important part of the history of modern library reference work in China, and have already become the Nanjing Library staff's lingering glorious memories. Here, the author proposes to carry on a preliminary review of 110 years of Nanjing Library's reference service, from different periods and several aspects since the building of the library, such as reference service measures, bibliography writings, reference service case, senior experts, and from four development trends of domestic and foreign cooperation, service for party and government organs, service for scientific research and production, new technology and new media application, previews and predicts the Nanjing Library's reference service in the next 3 to 5 years, so as to better understand the Nanjing Library's history and process of library reference service, motivate the posterity, don't forget to beginner's mind, and move on. 


\section{Nanjing Library Reference Services Yesterday Jiangnan Library reference services}

During the Qing (Guangxu) Dynasty, Liangjiang governor Duan Fang (1861-1911) visited Europe, praised the library after returning "opening mind, and improving civilization", decided to set up Nanjing Library. In November 1907 (September of lunar calendar), he employed Miao Quansun, a compiler of the Imperial Academy as agent. Before that, he also "went to Zhejiang together with Chen Shanyu (Chen Qingnian)", purchased the books of Qiantang Ding Bing's Baqianjuanlou using more than 73000 yuan. After a period of time of borrowing the back of the building of Nanjing Bureau of Autonomy at the original Qi Jia Wan for collection, it was determined to choose Bo Mountain Garden original Xi Yin Academy as the Library's location, plus recycling site of Shangyuan Higher Primary School (now No. 9, Longpanli Nanjing, office builiding of Jiangsu Province Cultural Department) to repair two libraries. The buildings started in 1908, finished in the following year, and named "Jiangnan Library", officially opened in November. As the change of times, Jiangnan Library's name changed frequently in the next 20 years. Until October 1929, it has changed its name to Jiangsu Provincial Library of Chinese Studies. In October 1952, Jiangsu Provincial Library of Chinese Studies were ordered to merge into the National Library of Nanjing which evolved from original the National Central Library (Records of Nanjing Library Editorial Group, 1996: 3-8). In addition to purchase from Ding Bing six hundred thousand volumes, the library also widely collected from the provinces to buy books, accept donations, such as buying Zhejiang Yao Shi collection 1011 kinds, Anhui Xu Shi 641 volumes that both total have literature books nearly one hundred and thirty thousand volumes (Zhang and Li, 1992: 55). On July 1, 1927, the famous historian Liu Yizheng served as director. He enacted regulations, opened reading, conducted research, wrote books and set up a theory, and was very prestigious. He made the renamed Jiangsu Provincial Library of Chinese Studies entered a stable period of development (Nanjing Library, 2006: 1). In 1937, after the outbreak of the Anti-Japanese War, while campaigning, collection books also have been repeatedly destroyed or lost. After the victory of Anti-Japanese War in 1945, for the recovery of Jiangsu Provincial Library of Chinese Studies, bookshelves and other equipment, he did not hesitate to kneel to the officials, and finally realized his wishes. A survey showed that the library had a total of one hundred and eighty thousand books at that time. On August 1, 1946, the library reopened after finishing the books arrangement (Records of Nanjing Library Editorial Group, 1996: 8).

Jiangnan Library reference service measures and bibliographic works. The Library provided with five reading rooms, that is general reading room, reference reading room, magazine newspaper reading room, special laboratory, children's reading room, and opened the seven hours a day, 8 am to $12 \mathrm{am}$, and $2 \mathrm{pm}$ to $5 \mathrm{pm}$. In June 1941, it opened to the full day. It also had four reading rooms outside the library, 16 itinerant libraries in some schools. It formulated organized regulations, general principles, each section's (internal institutions) business rules, reading notes, borrowing rules, special laboratory rules, reference reading room rules, general reading room rules, magazine newspaper reading room rules, children's reading room rules, authorities groups' borrowing rules and other regulations. For example, special laboratory rules laid down "Whoever want to enter the room must have one of the following qualifications: (1) Graduates of domestic and foreign university; (2) Graduates of domestic and foreign higher normal or special school; (3) A former high school teacher for more than two years; (4) Have the same degree equal to (1) or (2)." (Yang and Han, 1985: 190, 211) On August 14,1933 , the special library code reported to the approval of Jiangsu Province Department of Education had set a rule that "In order to encourage the young readers who have no way, the library selected and stored several kinds of books on Chinese studies initial must read, which can give to take time off to read according class, search gradually to further studies." (Wang, 2014: 315) Since 1928, it reorganized the original collections, determined in the collection of 
rare books publishing. As of 1934, the publications had amounted to more than 50 species of rare editions, including: "Bo Shan Shu Ying (Song and Yuan Version)" three copies, "Poetic Drama in Yuan and Ming Dynasty" six copies, "Letter of Celebrity Stocked in Taofeng Building" eight volumes, etc. Since November 1928, the annual issue of the Jiangsu Provincial Library of Chinese Studies has been published. After that, the Library edited the 24 volumes of "General Catalog of Jiangsu Provincial Library of Chinese Studies", and collected a total of 200,000 volumes from four classes, thus forming a complete set of bibliographic systems (Yan, 1983: 69).

Jiangnan Library reference service cases and senior specialists. For a long time, the story of deputy director of Jiangnan Library, Mr.Chen Qingnian had always been a favorite tale eulogized by our diplomats and reference librarians. Mr. Chen had used the library's rich collections to successfully solve the problem of foreign affairs together, maintaining our country territorial integrity. He was "deep in historiography, knowledgeable, and his essay was highly-organized".

At that time, there was a Japanese businessman named Nishizawa had seized Dongsha Island, the territory of our country by force. Huguang governor Zhang Renjun argued with him but was refused many times. Nishizawa "only knew Chinese annals detailed land, and most islands in the sea were neglected inadvertently". So he kept annals recorded as convincing credentials, and his cunning words showed his malice. After checked Guangdong Province annals without gains, Zhang Renjun ask Chen Qingnian help through Liangjiang governor Duan Fang (Xu and $\mathrm{Xu}$ 1996, 1-2). After ordered Mr. Chen Qingnian excited in indignation, sunk in the group of books, "inspected all hydrographic various books in his house, saw The Hydrographic Chronicles and the Coastal Situation Map drawn by Chen Lunjiong in the Yong Zheng period, which showed that to the west of Huizhou Port of Jiazi, China had a Dongsha Island in the Ming Dynasty, Tian Wei Biao Island is to the northeast, Nan Jie Island is to the southwest. Where the Kesh pressed down in the South China Sea is its location, which is belonged to China undoubtedly". He checked out The Hydrographic Drawings written by an English man called King John to make the same proof. At last, he forced Nishizawa admit Dongsha Island sovereignty belongs to China by hard facts, won the foreign court, forcing Japanese businessman exit Dongsha island. Chen Qingnian's reputation ran through both at home and abroad, also enlarged the influence of Jiangnan Library in the world (Xu, 1995: 53-54).

- Mr. Miao Quansun (1844-1919), famous modern historian, educator, bibliograph and library scientist of China, who had successively presided over for two modern libraries of great influence in our country, known as the "father of Chinese library". Since 1985, he accepted Qing government minister Zhang Zhidong's appointment to auspice Jiangning Zhongshan College. For advocating the new change, the college renamed Jiangnan High School and Mr. Miao Quansheng changed to the supervisor. In 1907, Liangjiang governor Duan Fang employed Mr. Miao as agent (director) of Jiangnan Library, so he quitted the school supervisor to deal with the library matters only. Together with Chen Qingnian, he went to Qiantang repurchased the books of Ding's Baqianjuanlou, laid the book foundation of Jiangnan Library. In the third year, he received orders to transfer to Beijing make preparations for the Capital Library (Jiangsu Provincial Department of Culture and Nanjing Library, 2012: 351-353). Because $\mathrm{Mr}$ Miao Quansun himself was the bibliography expert and had even helped Zhang Zhidong compiling famous selected directory "Shu Mu Da Wen", also provided comprehensive bibliography of ancient books "Yi Feng Cang Shu Ji" and "Bibliography of Faculty Library Rare Books of the Qing Dynasty", etc. Therefore the Jiangnan Library cataloguing work was of more standardized. In 1910, the Library set cataloguing department, and compiled "Bibliography of Jiangnan Library Rare Books" (one volume), "Jiangnan Library 
Bibliography" (eight copies), laying a solid foundation for revealing the collection and conducting reference service (Zhang and Ji, 1992: 56-57).

- Mr. Liu Yizheng (1880-1956), China's famous modern historians, writers, calligraphers, library scientists. Under his advocacy for non-local readers, as long as pay a certain cost, can the Library provide convenience of living library when reading. Whoever asked question, Mr. Liu entertained attentively, cared warmly and gave him enlightenment (Liu, 1980: 59-64). Just as the famous scholar Cai Shangsi (1935: 16) described in his book Scholars and Libraries, "Mr. Liu's knowledge is rich, his character is noble. Scholars living library reading like studying with teacher. In case of difficulty, you can query and make inquiries."

From the above brief description it is not hard for us to see that Jiangnan Library reference service germinated in the bud of Chinese library reference service. The reference service of Jiangsu Provincial Library of Chinese Studies was formed in the formative period of China's library reference service. Senior masters of the two libraries not only powerfully boosted the germination and the formation of modern Chinese library cause, but also made an indelible contribution to the germination and the formation of library reference service in China.

\section{National Central Library reference service}

In 1933, the National Government Ministry of Education set up National Central Library, appointed Jiang Fucong for the preparatory office director, rented houses owned by citizen for office space. In 1936, it moved to no.48 Chengxianjie street. On September 1 the same year, it opened to the outside (Records of Nanjing Library Editorial Group, 1996: 1). The Library based on the collection of the Ministry of Education in Beijing and 47000 copy books of the Ministry of Education in Nanjing and thousands of final imperial examination papers, accepted the publications of academic organizations around the world and domestic authorities and society, and legal deposit of domestic publishing institutions, and actively purchased a batch of precious carved stone rubbings of Tianjin Monteggia. It also published some important books by itself, took over charge of the international publication exchange business which originally belonged to Academia Sinica. By 1937, the collection of Chinese and western books and journals had amounted to one hundred and eighty thousand copies (Wang, 1991: 307-308). In August 1937, because of the Japanese bombing, the preparatory office moved westward to Chongqing, carrying selected 130 cases of books. On August 1, 1940, National Central Library formally established while the preparations ended. Jiang Fucong was appointed as acting curator, soon after he was appointed director. National Central Library moved back to Nanjing in 1946, began to receive books of the puppet government organs, Shanghai East Asia Tongwen Academy and "Ze Cun Stacks" at no. 2 Yihe road, to achieve more than 120 copies of collection, and then open Cheng Xian street reading room, Beicheng reading room and the central reading room. In April 1947, it built three layers of reading building in Cheng Xian street, and kept up till now. In the winter of 1948, National Central Library was ordered to select a collection of 130000 rare books, including all the rare books of "Ze Cun Stacks" to ship to Taiwan in three batches. Part of the staff went over to Taiwan. On April 23, 1949, Nanjing was liberated and the people's government took over the National Central Library (Nanjing Library, 2006: 1-2).

National Central Library reference service measures and bibliography. At the beginning of the National Central Library's preparation, it took "setting up a national library as the national center of books and reference for the capital institutions and personalities of various circles's research purposes" as the goal. On February 12, 1938, it moved to Chongqing, and its reference reading room was established on May 1 (Zhang, 1984: 459-460). In March 1939, because of enemy bombing of Chongqing, the preparatory office evacuated to a village in Baisha Town, Jiangjin County, and set up a public reading room and a reference reading room in Baisha 
Town. In January 1941, the Chongqing branch was completed in Chongqing's Liangfuzhilu (today's Changjiang Road), and the reading service was officially opened. "During the AntiJapanese War, some of the cultural activities of the central government of Chongqing were held in the Chongqing branch of the Central Library, which was called the palace of the culture in the war." (Records of Nanjing Library Editorial Group, 1996: 9-10)

During the preparation of National Central Library, "it had instructions according to the Ministry of Education in collaboration with the Commercial Press to copy Complete Collection in Four Treasuries of Wen Yuan Ge. By the year 1934, it had printed rare set in the early of 221 kinds, 1960 copies and 6 copies of each original sample of Complete Collection in Four Treasuries, namely Confucian classics, history, philosophy and belles-letters. After that, it took over the Classics Publishing House, renamed it to the Central Library Wood Printing Department. In 1934, since the Ministry of Communications sent letterpress printing machine, it set up the printing office to print official books edited on its own, periodicals and catalogs. Library science magazine Journal of Learning Vase was published in 1936." (Wang, 1991: 308) During the period of the war of resistance against Japanese aggression in Shanghai, the occupied area of Shanghai occupied a large number of old stocks in the market, and the Library secretly commissioned Zheng Zhenduo and Xu Senyu to be in charge of the acquisition in Shanghai. In order to prevent the loss of books, it is needed to cover the book stamp in books. But in the occupied areas, it was inconvenient to have the Central Library's name, so employed $\mathrm{Lu}$ Ji's words "standing in the central district to observe its mysteries", famous master Wang Fuan engraved inscriptions "Zhong Qu Xuan Lan" on a square stone implicating central to cover in the purchasing books. In case this batch of books destroy during the war, Zheng Zhenduo chose and photographed unique copies in time in Shanghai, and evolved Xuan Lan series name as "Xuan Lan Hall Series" from the collection of stamps "Zhong Qu Xuan Lan". (Records of Nanjing Library Editorial Group, 1996: 217) This patriotic act had already become a popular saying in Chinese modern and contemporary history of the library.

National Central Library reference service case and senior experts. At the beginning of the opening of the National Central Library, the books of the open reading were divided into reference, newspapers, periodicals and ordinary sections. Even during the war in Chongqing, there was a shortage of books, a lack of money and a narrow space, the Library insisted opening to the public. From May 1938 to March 1939, the number of the visitors was seventeen thousand six hundred and one. The reference reading room opened in Baisha Town in Chongqing is given priority to the western language books, taking the open system together with the public reading room, the average monthly received the readers more than seven thousand people; after the establishment of the Chongqing branch, it had also successively added the Chinese reference room, the west text reference room and so on the room, the average monthly received the readers more than 10,000 people (Yang and Han, 1985: 172). On the premises and adding reference books each year, bibliographic index, spreading the reference materials, brochures, reference service and so on, it had clear rules (Jiang, 1978: 362-379, 439-446).

- Mr. Jiang Fucong (1898-1990), pioneer of library activities. In 1930, he went to study in Germany, and was appointed as visiting librarian of the Prussian State Library. He graduated in July 1932, appointed by the Ministry of Education in the Process of the National Central Library in 1933. In 1940, he was appointed as director, and subsequently as the Library Association Council and other international organization official duties at home and abroad. His theory works of library science are "The Theory of Chinese Library Classification" "Method of Library Management" "Book and Library" "Zhen Zhou Ji", etc. He also compiled and printed "Yi Jing Ji Mu" "Si Shu Ji Mu" "Lun Yu Ji $M u$ " "Meng Zi Ji Mu" "Xiao Jing Ji Mu"and other bibliographies (Xie, 2005: 340-341). Mr. 
Jiang Fucong had always attached importance to and promoted library reference service. He had a detailed discussion in his "Zhen Zhou Ji" reading still has important guiding significance, and may be excerpted fragments as follows: "Book cataloging: In order to let readers pay attention to the collections, library should compile new books list and single piece or brochure bibliography. This special bibliography has different properties, which show data of certain subject or teach with the reading method of subject....." "Individual guidance: for the readers with purpose, it is very difficult to guide those readers with different ability, degree and hope. The first step to work as close to the reader, try to talk to, to clear its character and purpose of professional qualification and study time. Then according to education psychology and fully reference tool, contact the school education authorities and experts of the design practice of the way. If have no choice but to engage except special department to design for the study of the way, to whom we can't never find the general (Jiang, 1978: 363364).

From the above review of the history of the Library, it is clear that National Central Library's reference services also formed in the Chinese library formation, even during the period of AntiJapanese westwards Chongqing, very difficult period of less in the books, the lack of funds, small library building, often encountering the enemy bombing, the National Central Library's senior experts still opened to provide the reference service, which is mental commendable! It is worth learning.

\section{Nanjing Library Reference Service Today}

On April 23, 1949, Nanjing was liberated. On May 23, the Cultural and Educational Committee of Nanjing Military Control Committee formally took over the National Central Library. In March 1950, according to the official notification issued by the Bureau of Culture Relics of the Central Ministry of Culture, the Library changed its name to the National Library of Nanjing. Famous historian He Changqun was appointed as curator, while accepting the dual leadership of the Bureau of Culture Relics of the Central Ministry of Culture (after the Administration Bureau of Social Culture) and the Culture Ministry of Military and Administrative Committee of East China.

On January 1, 1953, the People's Government of Jiangsu Province was officially established. On July 6, 1954, the Ministry of Culture of the Central Government officially informed the Cultural Bureau of Jiangsu Province that the National Nanjing Library was changed to the Jiangsu Provincial Library, which was led by Jiangsu Provincial Cultural Bureau. Considering that the "Nanjing Library" has a high reputation at home and abroad, so it was decided to remain the only provincial public library named by the city name (Records of Nanjing Library Editorial Group, 1996: 11-13). The Library at the time was scattered in three places. No.66 Chengxianjie Street (original National Central Library) stored the main collection of Chinese and foreign books and periodicals after 1949. The main collection of ancient books was in 2 Yihelu Road (former site of the original Zecun Library). No. 9 of Longpanli (old site of Jiangnan Library) mainly collected the literature of the Republic of China (Nanjing Library, 2006: 2); The Library also had a reading room on Changjianglu Road, and several book circulation stations had been established in Nanjing. The Library had a collection of 2.4 million copies, and it was the largest in the provincial public libraries then (Records of Nanjing Library Editorial Group, 1996: 13). In 1959, it built its first formal stack room on No.66 Chengxianjie Street. In 1979 and 1982, there were eight storeys and five floors of the building. Between 1987 and 1994, Jiangsu Provincial Government had allocated funds for Nanjng Library to build two new buildings, successively at No.9 Longpanli and No.85 Hujulu Road, to collect of documents of the Republic of China and ancient books, greatly improved the condition of collections (Nanjing Library, 
2006: 2-3). By the end of 1995, it had reached 6.82 million volumes, second only to the Beijing Library and the Shanghai library, ranking third in the country (Records of Nanjing Library Editorial Group, 1996: 102). On December 8, 2007, the new building of Nanjing Library officially opened to the whole society. There were more than 3000 reader's seats, more than 4000 information points and free wireless coverage in the Library. After nearly a decade of development, as of the end of July 2016, the total collection of books had exceeded 11 million copies, ranking second only to the National Library and the Shanghai Library. Among them, 1.6 million books were ancient books, including 140,000 copies of the rare books; books of the Republic of China were 700 thousand volumes. Nanjng Library has really become the new coordinates of Jiangsu Province's cultural map (Nanjing Library, 2016).

\section{Nanjing Library reference service measures and bibliography.}

In 68 years' journey after the founding, with the recovery and development of national economy and the development of the political movement, Nanjing Library policy subsequently adjusted many times, the service content was also showing a lot of different, generally can be divided into the following stages:

- Recovery and early development (1949-1955): Early implementation of policy was giving priority to compiling old books, and doing mass work appropriately. So the Library finished the old books arrangement and adjusting the layout work on a large scale. Then it converted this work center of gravity to carry out new book reading room, gradually opened four reading rooms which mainly collected new Chinese popular book, set up several book circulation stations. Here's what it says: from 1949 to 1956, it was a productive period for compiling the bibliography. According to The Compilation of the Bibliography of Nanjing Library (1949-1959) published in March 1960, there were 240 kinds of bibliography in 10 years. According to The Compilation of the Bibliography of Nanjing Library (1960-1964) published in 1964, there were 120 catalogs in 5 years. Therefore, it is not difficult to calculate that in the first 17 years before "Cultural Revolution", the Library compiled 360 bibliographies and indexes. How spectacular it is (Records of Nanjing Library Editorial Group, 1996: 162). Among them, bibliographies have had a certain influence in the country are: The Books Review Data Index, which was founded in 1951, died in August 1960, published a total of 58, and distributed throughout the country; Jiangsu Decade (1949-1958) Socialist Revolution and Socialist Construction Data Index, internal print published in October 1959; New Books and Periodicals of Agriculture(quarterly), which was published in September 1965 and closed in 1984; Nanjing Three Systems Library Foreign Language Science and Technology Periodical Joint Catalogue, published in late 1957 (Jiangsu Provincial Department of Culture and Nanjing Library, 2012: 97-102).

- Serving scientific research (1956-1963): In 1956, "for scientific research service" became the Library policy during the period. Therefore, in order to strengthen the reference reading, it set up five specialized reading rooms, expanded the lending work to the government agencies and organizations, and established the inter-library loan relationship among 41 public libraries and university libraries. The guidelines for scientific research services were affected after "The Great Leap Forward" in 1958.

- Serving "outstanding politics" and the third revolution (1964-1977): After 1964, the atmosphere of "outstanding politics" became more and more intense. In the eleven years since the beginning of the "Cultural Revolution" in 1966, Nanjing Library business had been severely damaged again and again.

- 30 years of reform and opening up (1978-2008): In 1978, after the Third Plenary Session of the 11th Central Committee of the Chinese Communist Party, Nanjing Library has established the direction of serving socialist spiritual civilization and material civilization. According to the discussion of the Secretariat of the Central 
Committee of the Communist Party of China in May 1980, and the spirit of The Library Work Report Outline passed by the Secretariat, the Library gradually transferred its focus to serve the economic construction. Therefore it increased the foreign science and technology periodicals subscription fees, strengthened the reference work. In 1983, it opened a foreign books reading room, literature retrieval room, social science reference reading room, etc. Since 1988, the Library started to issue the library card unrestrictedly, implemented the open-shelf service, SDI, audio-visual services and variety of ways, among which the way of service of regularly holding the latest foreign technology, light industrial art book fair in the cities and counties of Jiangsu Province was welcomed by many grass-roots library. Since the nineties, the Library actively supplied for the communist party leadership authority decision-making information service, and distributed Nanjing Library Information Report (which has changed its name to Information Quick Report, Information Fax, and Information Gathering one after another), is well received by the leaders at all levels (Records of Nanjing Library Editorial Group, 1996: 16-17). Since March 1998, reader can apply for a library card with his ID card. At the beginning of 2000, on the basis of the original literature and art books and various new books opening to the outside, the natural science closed stacks were turned into open stacks. In March of the same year, the Library realized "One Card Pass". The average loan volume of 2000-2005 reached 264 thousand person times, 403 thousand volumes, compared with the previous decade, the number of lending person times increased by 73 percent and the number of lending volumes doubled (Jiangsu Provincial Department of Culture and Nanjing Library, 2012: 540-552). From 1996 to 2005, the Library won a special prize and 9 first prizes in the provincial public libraries outstanding service achievement award at one to three sessions (Nanjing Library, 2006: 54-55). In 2008, it led the establishment of the Jiangsu Public Library Joint Reference Network. At that time, the total collection of the Library had reached 8.67 million copies (parts).

This stage focuses on the following five aspects of bibliography:

1. Participating in the compilation of The Chinese Ancient Books Bibliography. The work started in March 1978 in the whole country after the meeting in Nanjing. Nanjing Library is one of the leading group members of rare books bibliography editing work, and as a big cooperation zone of the east China team leader. Pan Tianzhen (the former deputy director of the Library, version scientist), Shen Xieyuan, Gong Aidong (formerly deputy secretary of Nanjing Library party branch), Jiang Ling attended the work. Pan Tianzhen was appointed deputy editor of the editorial board, and was responsible for the review and finalization of the Ziradical. Beginning in 1988, the Confucian classics department, the history department, the Ziradical, and the category of literary works successively published. In March 1995, Pan Tianzhen was awarded a major contribution award by the Ministry of Culture and the National Ancient Book Organizing and Publishing Planning Group, Shen Xieyuan and Gong Aidong were awarded outstanding contribution award.

2. Compilation of memorial personal writings and bibliography. Specially: The Catalogue of Lu Xun's Written Translation and Research Documents, which was compiled in September 1981; Index of Qu Qiubai Research Data compiled in 1985; The Index of Dr. Sun Yat-sen's Works and Research Materials, which was compiled in October 1986; In 1997, the compilation of The Index of the Research Materials of Deng Xiaoping, etc. In memory of comrade Zhou Enlai's birth in one hundred, the Reading Department of Nanjing Library was commissioned by the Jiangsu Provincial Party Committee Propaganda Department, to bear the editor of the Index of Nanjing Library's Zhou Enlai Works and Research Data. The book was officially published by the Jiangsu People's 
Publishing House in February 1998, prefaced by Gu Hao, former deputy secretary of Jiangsu Provincial Party Committee, includes collection published since the 1930s, 338 kind of Zhou Enlai's writings, learning and introducing book, 476 publication of newspapers and magazines since the founding of the People's Republic of China, altogether has the library books and pictures and marked script data directory 1396 article, and the literature review series Zhou Enlai and Jiangsu. In 1999 it won the first prize of the first public library service excellent achievements in Jiangsu Province.

3. Compilation of Index of Library Science Papers. On the basis of Library Science Papers Index(1) edited by Mr. Li Zhonglv at the beginning of the founding of new China and Library Science Papers Index(2) proposed by Mr. Qian Yaxin in 1957, since 1982, the Library continuously published six books of Library Science Papers Index, which includes 1949-1994 professional magazine published in library science, library data sets and some non-professional newspapers in library science, bibliography, edition science, information science and so on paper, respectively published by Bibliography and Document Publishing House, Jiangsu Society of Library Science and Beijing Library Press.

4. Compilation of library catalog and index. In particular: The Catalog of Foreign Language Technology Journals in Nanjing Library, edited and published in 1981; The Chinese Newspaper Catalog Before the Founding of PRC in Nanjing Library edited and published in 1982; The Catalog of 40 kinds of Chinese Books in Nanjing Library printed and published in 1990; The "Small and Medium Classification" Book Catalog edited and published in 1996, etc. Union catalogs edited in chief or participated in continuous by the Library were: The Nanjing Library Catalog of Foreign Language Periodicals of Science and Technology in Combination with Three Big Systems, New Foreign Language Book Joint Catalog of The Three Big System Libraries in Nanjing.

5. Compiling the catalog to cooperate with the memorial activities. In 1981, in order to commemorate the 70th anniversary of the 1911 Revolution, The Catalog of the Revolution in 1911 was compiled; In 1997, The Bibliography of the Special Study on the Long March of the Red Army in Nanjing Library and Nanjing Library Research Bibliography of Hong Kong were compiled. According to The Outline of the Implementation of the Education of Patriotism issued by the Central Committee of the Communist Party of China and spirit of three years implementing plan to develop the patriotism education in Jiangsu Province, the Library accepted the commission of the Jiangsu Provincial Party Committee Propaganda Department, and its Reading Department took on the task of compiling of The One Hundred Kinds Recommended Books of Patriotic Education in Jiangsu Province. Lasted more than half a year, before and after the extensive investigation and study, the Department asked for suggestions of publishing departments experts and professor, set out the tentative program of recommended books (book list). Based on the 100 kinds of patriotism education books catalog of the national primary and middle schools recommended by the CPC Central Committee and other five departments, the Propaganda Department of the Provincial Party Committee and other nine units carefully reviewed, and finally determined the production. On June 8, 1995, Jiangsu Provincial Party Committee Propaganda Department, the Education Committee of Jiangsu Province and Jiangsu Province Cultural Department, nine units jointly issued a Notice about One Hundred Kinds of Patriotism Education Books Recommended to the Provincial Youth, which require the primary and secondary schools, basic units to make three years plan of study, step by step, multi-level and give priority to organize them to read. After The One Hundred Kinds Recommended Books of Patriotic Education in Jiangsu Province publishing, librarians of the Reading Department of Nanjing Library also compiled more than 60 kinds of book executive summary which serialized in The Service Herald Newspaper, and in 1999 won 
the first prize in the first public library in Jiangsu Province outstanding service achievements (Jiangsu Provincial Department of Culture and Nanjing Library, 2012: 99103).

- Development in the Past Nine Years (2009-2017)

This stage can be divided into three periods:

1. During the 2009-2010: Nanjing Library daily received readers more than 6000 persontime. The Library's website hit 2.18 million, and had 6056 hits per day. It successively held celebration of the New Year and the Spring Festival, the World Book and Copyright Day, "Colorful Summer" children's summer activities and other large readers series activity, held public computer training for the elderly, rural migrant workers and other vulnerable groups, continued to make Nanjing Library Lectures and Nanjing Library Exhibition brand, and was commended as Jiangsu outstanding forum by Jiangsu Provincial Party Committee Propaganda Department, also awarded the "National Reading Demonstration Base" successively by the China Society for Library Science. It compiled and published The Second Batch of National Rare Ancient Books List of Jiangsu Province, participated in the edition of A Branch of Great Dictionary of Chinese Culture • Military - Military Character and continued to make The Modern Chinese Literature Image Database and other special databases.

2. During the "Twelfth Five-Year"(2011-2015): Nanjing Library purchased books 200,000 copies annually. The cumulative purchasing books reached 1 million copies in five years. By the end of 2015, the collection of printed books reached 10.92 million copies, electronic books, 1.4 million copies, self-built and outsourcing digital resources is 78.2 TB. The average annual receipted readers were 3 million person-time. A total of 503,000 library cards were issued for readers. The Library completed the renovation of the readers' self-taught room, electronic reading room and carried free opening. In addition, 180 seats were added to the channel of each floor, making the total number of self-taught seats in the Library to 600 . At the same time, the number of seats in the public leisure area has been increased by 320, making the total number of leisure seats increased to more than 500. The original "Visually Impaired Person's Library" was moved from one floor to the B.M FLOOR beside the west gate, so as to supply convenient access to visually impaired readers. Many times through the way of auction, it supplemented a batch of more precious ancient books, among which the Song engraved $\mathrm{Li} \mathrm{Bu}$ Yun Lue became the new key highlights of the collections. In 2014, it bought a photocopy of the Complete Collection in Four Treasuries and opened a special room for readers to study and read, which attracted wide acclaim from the society. A total of 56 "Nanjing Library Circulation Service Points" have been established in the Province, which has been unanimously affirmed by library experts.

Led by Xu Xiaoyue, Nanjing Library curator, Nanjing University philosophy professor, doctoral supervisor, for the first time in the history of Nanjing Library, the Library success to declare the major social science fund projects in Jiangsu Province, Jiangsu Monograph on Bibliography. The Rare Local Records Collection of Nanjing Library (a hundred and seventy volumes) won the first prize in the 13th outstanding achievement award of the philosophy and social science of Jiangsu Province. Presided by Fang Biaojun, party member of the Cultural Department of Jiangsu Province, Party secretary of Nanjing Library, Study on Free and Open Public Cultural Institutions and Public Services which was important project of Ministry of Culture, evaluated by experts as the top project. It published The Nanjing Library Precious Manuscript Periodicals, National Condition Survey in the 1930s, Biography of the Chinese modern Character, etc. The 
total number of units and the total number of ancient books, which are leading the Province to complete the catalog of ancient census registration, are among the highest in the country. The Library exchanged views and reached an intention with The Library of Congress and The Huntington Library to expand the exchange of books, databases and technicians study, held talks with The University of Maryland in the United States on literature exchange and the restoration of ancient books. Signed a strategic cooperation agreement with OCLC (On-line Computer Library Center), became a member of OCLC, and received many visits from OCLC related principals.

3. From the First Year of the 13th Five-Year Plan up to Now(2016-2017): According to the "Thirteen-Five"Plan for the Cultural Development of Jiangsu Provincial Department of Culture, Nanjing Library made in time its "Thirteen-Five"Development Plan, which taking the "Domestic first-class, internationally advanced" as the overall goals and four main objectives at the end of "Thirteen-Five"Plan, and substantial progress has been made at the start of the implementation:

In the project of "Precision Service", the Library has launched the "Tao Style" service project, and has promoted the expansion of the children's library project. Its "Tao Style - You Choosing Books, I Pay the Bill" signing and the launch of "Gentle Breeze Book Hall" service, realized the synchronization for reader's borrowing and book publishing, meeting the demand of the personalized, timeliness reading. It is a cultural service to benefit the people jointly launched by Nanjing Library and the Phoenix Publishing Media Group. Readers can directly choose their own favorite books, and borrow them through the way of recommendation, at Nanjng Library's "Gentle Breeze Book Hall", Nanjing Xinjiekou flagship store of Xinhua Bookstore or Phoenix International Book City, so as to realize the rapid purchase and reading of "wysiwyg". (Yang, 2016) In the project of "Library of the Library", The Chinese Ancient Culture Studies Library of Nanjing Library opened on October 12, 2016. The "Xuan Lan Hall" in The Chinese Ancient Culture Studies Library, as a rare exhibition hall of the Chinese Ancient Culture Studies, shows the rare ancient books of Nanjing Library. "Hall of Cherishing the Time", as the special precious historical documents reading area, electronic-reading area and original manuscript reading area, it holds a full set of photo-print Complete Collection in Four Treasuries and finished books of "The Re-engineering Project of Good Edition". In addition, the area is equipped with series materials of rare local records, Tibetan Tripitaka, Taoist Canon and other religious texts, the related reference books, and other different Wenjin Pavilion, Wenyuan Chamber copy and renew imperial repair, the imperial Cun $M u$ series. There are also new prints of ancient literature, New Republic of China printed literature and new Chinese Studies resources display areas. The Chinese Studies Library provides 50000 new copy of the ancient books and 30000 volumes of new literature of the Republic of China, more than 10000 kinds of "new Chinese studies" books, panorama shows the Chinese culture broad and profound, supplies accurate service for different people. Through the activity of the Chinese learning experience, it carries forward the fine tradition, cultivates the public's cultural identity, to promote the popularization of Chinese learning and sharing (Chen, 2016a). After more than six months' elaboration, "Childrens' Library of Nanjing Library" officially opened for free on October 12, 2016, which is suitable for the children from 0 to 6 years old. Since then, the children's borrowing service is covered by all ages (Zeng, 2016).

Nanjing Library has uploaded all the data of Chinese books collection after 2007 to OCLC WorldCat (world's bibliography) ahead of the end of "Thirteen-Five". By international interlibrary loan and literature transferring, it will improve the capacity of the international spread of Chinese culture. There are 522 rare ancient books were chosen into The National Directory of Precious Ancient Books. The 24-hour self-service library and evening reading room have also been added, and the number of readers' seats has increased to more than 4,000. As of July 
2016 , the total number of readers has reached 860,000 , reaching 7,000 readers per day. As the main participation units, Nanjing Library participates again the key cultural project "Jiangsu Context Collation and the Research", hosted by the Government and the Provincial Party Committee Propaganda Department of Jiangsu Province, bearing the "Bibliography" research task (Chen, 2016b). Under the situation of creating a new situation of reader service and bibliography, its reference service constantly rides on. Since the founding of the People's Republic of China, especially in the history after entering the second hundred, Nanjing Library also has obtained many encouraging results and great progress.

\section{The Reference Service Case and Senior Experts of Nanjing Library.}

The reference service of Nanjing Library has experienced the process from general consultation to special consultation, from simple consultation to complex consultation. In the 50s of last century, consulting times from 161 times in 1954, raised to 400 in 1957. In the 60s, its reference librarians paid attention to finding clues for readers in the reference room using catalog and reference books. Five or six years before the "Cultural Revolution", they solved difficult consulting about 500 times a year. After the start of the "Cultural Revolution", it was not normally open. After the reopening in Sept 1977, it set number of full-time reference librarians, as chief of philosophy and social sciences, natural sciences, special collections reading room and ancient book reading room's reference service. Till to 1979, the consulting number raised to about 300 per year. In 1983, when the new building was opened, the second floor lobby was the general directory room and a directory consultant was established. In the 80s, the Library Added thematic reading room and science and technology book fair tour. Its Special Collection Department and Ancient Book Department provide more information for the addendum to the history of local records and academic research across the country, and the whole consulting service quantity was rising. According to statistics, after 1980, the annual answering oral consultation and topic consultation were about 1500 times. In the 1990s, in addition to doing a good job of consulting services in the library, it also went to the street to answer readers' inquiries during the library service publicity week. From 1996 to 2005, the average annual consultation was 60,000. In 1997, the first class station of Nanjing Library was officially opened. In 1998, it set up electronic literature search room, through the LAN for readers in library provides the Chinese and foreign national patent and chemical abstract, international PhD thesis, Chinese academic journals (CD-ROM version), such as more than 10 kinds of retrieval service of electronic literature. At the same time, it provided online information retrieval service. In December 2003, the Library set up online information desk on its web site, through the "frequently asked questions (FAQ)" and forms consulting, achieved the result that through the network to the readers at home and abroad to provide advisory services (Nanjing Library, 2006: 58). In 2005, its online reference service had joined the "Shanghai Library Online Joint knowledge Navigation Station", "Sun Yat-sen Library of Guangdong Province Joint Reference Network. In August 2008, it purchased the digital resource and reference platform software, led 13 city libraries to form the joint reference network for digital information resources co-construction and sharing of public libraries in Jiangsu Province. In July 2010, the network recruited Yizheng City Library and other six county libraries (Wang and Tang, 2012: 311-318). Thus, the Library entered a stage of cross-regional cooperation consulting online.

On December 1, 2012, the new Joint Reference Network of Jiangsu Public Library officially opened, which supplied readers with simple operating, practical digital portal and the unified retrieval platform. The integrated digital resources of the Library are: Wanfang Standards Database, China Scientific \& Technological Achievements Database, China Science Periodical Database, China Dissertation Database, Database of Science and Technology Periodicals of WIP, Beijing University Fayi Database, DRCNET, MCDB. The Network accessed to the cloud service 
system at the same time, which can help the reader free remote access, seamless access to the required information and remote online reference consultation and literature transferring services, so as to provide more effective use of units to provide information resources and reveal the literature, expand access to literature resources, improve public service capacity of the library collection literature units in the whole province. As of September 24, 2013, the new Joint Reference Network of Jiangsu Public Library had answered reader online questions 13678, passed documents 25037 references. From October 2013 to October 2016, 179,783 items of consultation and literature were completed online. At the same time, from January 2011 to October 2016, the Library answered readers' questions 1997 from the reference desk at the Joint Knowledge Navigation Station of Shanghai Library. The Library finished consulting and passing the original texts 5044 from the Network of Jiangsu Province Engineering and Technology literature Center, which was an information retrieval and service platform coconstructed by university libraries and research institutes in Nanjing area.

- In August 1977, the Nanjing 741 factory tried to make a new light source for the special requirements of "fine tube neck, three base colors, no ultraviolet output and high concentration of light" for Mao Zedong Memorial Hall. In accordance with the requirements of engineering, the deadline of searching materials is only three days. In these three days, it would be difficult to consult thousands of copies of western, Russian and Japanese documents in the last ten years. To this end, the Library took the method of both advisory and thematic reading to let librarians and readers to identify, judge the literature, expand the finding clues, finally extracted valuable information more than 30 articles, delivered the factory to use. Among the 30 articles, there are US Patent "Lighting Gas", "Electric Light, Discharge Apparatus", Japan Patent "Optical Device" "Paint", "Lighting", Japanese publication Optical Technique, The research of the coating, Coating Technology and other literature contained in such documents. The new light source was sent to Beijing for use on time after the factory's research and trial.

- In June 1981, Mr. Cao Jin from Xian Institute of Raw Lacquer came to query information about the history of raw lacquer, Japanese books about lacquer tree cultivation and paint processing, who had been to Beijing and other places, and then traveled to Nanjng Library to do the last query. By consulting Aggregation of Series of Chinese Ancient Books, Tai Ping Yu Lan, Title Record of Chinese Modern Journal and so on reference books, the librarians found the books and periodicals about the raw lacquer, sumac cultivation and utilization, among which there are Xiu Shi Lu written by Huang Cheng in the Ming Dynasty, Qi Jing written by Zhu Zundu in the Song Dynasty, Plant Paint Method published in Agronomy in March 1898. From the collection of East Asia Tongwen Academy, they also found Japanese Lacquer published in 14 years of Shouwa, China Important Resources Research published in 16 years Shouwa and so on eight kinds of precious materials in the special collection of the East Asia Common Culture College, so as to meet the requirements of the readers.

- In May 1982, the Xinjiang uygur medical history investigation team came to Nanjing to search for ancient uygur medical historical materials. The team first went to the Intelligence Agency and did not gain the results, later went to Nanjing Library to query. Consultant Yang Shiming found dozens of data directory from 18, 19th century foreign version about Chinese frontier travels abroad. According to the directory, he and other consultants found domestic rare English books in Nanjing Library special collection, translated all the English books which have 200000 words into Chinese, and provide for the use of the team. So, the team got rich first-hand information and contributed to the mining and finishing uygur medicine heritage.

- In 1990, the Automatic Controlling Department of East China Institute of Technology had completed the developing task of "Multi-Sensor Multi-Target Tracking Processing under the Data Fluid". In order to confirm the topic in the field of anti-aircraft gun 
surface-to-air missile track processing technology advanced, novelty assessment report is needed to be done. After accepted the task, the reference librarians of Nanjing Library selected "tracking" "path identification" "data stream processing" "multi-sensor and multi-target" and other related keywords and categories, from the US Government Research Report and Index, Index of Engineering, Science Digest, Index of Conference Papers, Dewinter International Patent System, they found out 238 similar articles. Via analysis and appraisal, they found that although all kinds of track processing method is different, but are "batch" method, the scientific research method of "data stream processing" had obvious novelty, and issued the authoritative novelty assessment report (Records of Nanjing Library Editorial Group, 1996: 156-159).

Senior Experts of Reference Services of Nanjing Library:

- Mr. Wang Changbing (1904-1988), China's famous educationist and library scientist. Graduated from Wuchang Wenhua Library College in 1926. At the same time, The China Foundation was preparing the Beijing Library and he was recruited into the catalog section to take charge of the cataloging of the western language. When the Reference Section was founded in 1928, he became the first reference librarian, and the next year was appointed as the first reference group leader, and served in it till to August 1932. Then he went to USA to study the library science there (Li, 2012: 36-42). He was awarded a master's degree in library science in 1934. In July of the same year, he went to the Oriental Department of the Library of Congress to do the Chinese book cataloging. Since autumn 1941, he worked in National Institute of the Social Education in China as a professor and director of the Department of Museum and Library. Until the founding of new China, he cultivated a group of senior professionals of library science, and made outstanding contributions to library science education. He was appointed deputy director of Nanjing Library in 1955 and was appointed the director of the library on March 5, 1957. In March 1956, he was the first to advocate that provincial public library should serve the scientific research, and four months later the Ministry of Culture made clear the policy of "scientific research service". From 1956 to 1966, Nanjing Library had been carrying out the scientific research service, and became a model for the public libraries of the whole country. In April 1956, he founded the Nanjing Regional Library Network, led the union catalog making, inter-library loan and contract signing, which made the Nanjing area's periodicals procurement coordination, books and periodicals joint catalog making, inter-library loan had been one of the leading enterprises in the national work. In 1984, he was hired as honorary curator from the leadership post (Jiangsu Provincial Department of Culture and Nanjing Library, 2012: 365-366).

- Mr. Qian Yaxin (1903-1990), China's famous library scientists, bibliographer, and the Grand-master of library science. In 1922, he graduated from the First Normal School of Jiangsu Province in Suzhou. He was admitted to Shanghai Datong University in the same year, and he dropped out of school a year later. In 1925, he was inserted into the Department of Library of Shanghai National University. In 1926, he was admitted to the Wenhua Book Branch of Huazhong University, and after graduation in 1928, he worked as a teacher in the library or department of 9 institutions of the Zhongshan University in Guangzhou. In 1950, he transferred to Nanjing Library to serve as director of the foreign language cataloging department, reading department, director of scientific methods and acting director. He was engaged in the library work in the past 60 years, committed to the library cause, dedicated to the library science education and talent cultivation, committed to bibliography and library science research, wrote more than 200 words of monographs and papers. Main monograph has Compiling Method of Pinyin Author Number, Index and indexing, Index of Tai Ping Yu Lan, Studies of Zheng Qiao's Jiao Chou Lue , Three Qi Library in East Zhejiang and Academic Research, Science and Technology 
Periodical Management and Utilization, and Mr. Du Dingyou's Posthumous Manuscript Selection, etc. In addition, there were 166 papers published, which including library science, classification, bibliography, indexing, Chinese character screening, textual criticism and library science education, etc. (Jiangsu Provincial Department of Culture and Nanjing Library, 2012: 364-365)

- Mr. Liu Dingsheng (1913-2006), graduated from the History Department of Nanjing Central University in 1931. After graduating from the school, she had been working and teaching in the Suzhou Women Middle School, the History and Geography Department of Zhejiang University, the National Chongqing Compilation and Translation Institute, Boxi Branch of the Central University and Jiangsu Provincial Library of Chinese Studies one after another. From 1953 to 1988, she worked in the Nanjing Library work, as deputy director of the former Ancient Books Department, deputy director of the Scientific Method Department, deputy director of the Bibliography Department successively. She had participated in the revision of Jiangsu Tongzhi, published Liu Yizheng Brief Biography, Mr. Liu Yizheng's Chronicle, which are authoritative literature on the life and academy of Liu Yizheng. She also published a series of articles recalling the predecessors of the Library (Jiangsu Provincial Department of Culture and Nanjing Library, 2012: 367-368).

- Mr. Pan Tianzhen (1919-2004), graduated from the Department of History of National Central University in 1945. He had been teaching for five years after graduation, focusing on the history of the two Han Dynasties. In the early 1950s, he transferred to the Nanjing Library and followed the director He Changqun in administrative work. After working in the business, he served as director of the Reading Department, director of the Bibliography and Reference Department, director of the Ancient Books Department and curator of Suzhou Library. Since 1977, he had participated in the compilation of The Bibliography of Ancient Chinese Books, which lasted more than 20 years. In 1980, he took charge of the deputy editor of The Bibliography of Ancient Chinese Books, and was responsible for the finalization of the sub-directories. In 1995, he was awarded the major contribution award by the Ministry of Culture and the National Ancient Books Organizing and Publishing Planning Group. In 2002, he published Pan Tianzhen Anthology which compiled his main papers written in his spare time about the books preparation, production, collection and utilization history (Jiangsu Provincial Department of Culture and Nanjing Library, 2012: 368).

- Mr. Yang Shiming (1924-2008), studied in the Economics Department of the University of China, Beijing in 1943, worked at Shanghai Administration of Highway Road Machinery Reformation Training after graduation. He had been working in the Nanjing Library since 1953. He engaged in reference service, and his main research achievements in information retrieval, especially to the DERWENT world patents integrated retrieval system published in UK. He obtained the first prize of papers of Information Society of Jiangsu Province in 1988 and 1992 separately. In August 1985, when Mr. Mailer, member of the Board of the DERWENT Company came to China, he especially met with Yang Shiming. In order to adapt to the needs of readers, according to the practical application and the teaching experience for many years, Yang Shiming wrote the book of 150000 words DERWENT World Patents Retrieval System and Its Application, and published it by Nanjing Institute of Science and Technology Intelligence inside in November 1986. The book theoretically analyzes DERWENT system's general structure, the retrieval language, layout principles, retrieval operations such as special topic, discusses on the various laws in detailed, and is especially suitable for the manual retrieval. In 1991, he edited and published the 1.2-million-word book DERWENT World Patents Retrieval Language Manual by Zhenjiang Institute of Science and Technology Intelligence inside, which focus on the introduction of system's major retrieval 
language, and supplied more convenient manual retrieval. For filling the blank of domestic and foreign research on Chinese social sciences citation index, Nanjing Library founded the "Establishing CSSCI new information retrieval system research" team in 1995, as the second head of the project, Mr. Yang drafted the theme report of the project----the feasibility report of Chinese Social Science Citation Index (CSSCI), which laid a foundation for the subject passing provincial appraisal, and gained the collective and individual prizes of progress of science and technology of Jiangsu Province (Records of Nanjing Library Editorial Group, 1996: 235-236).

- In the history of Nanjing Library, there are two senior experts, Mr. Qiu Keqin (19191989) and Mr. Lu Zibo (1936-), who have a good study of reference service and its related business, or are fruitful in the service management, training talents and so on (Records of Nanjing Library Editorial Group, 1996: 236-239). Other senior specialists who long-term worked in Nanjing Library reference service line and get high grades are Mr. Bei Zhiquan (1927-2011), Mr. Jiang Shirong (1912-2000), Mr. Zhu Gainan(1919-), Mr. Ji Weizhou (1922-), Mr. Shao Yanmiao (1930-2000), Mr. Du Xingfu (1919-2016) and others. (Records of Nanjing Library Editorial Group, 1996: 240-242, 251)

To sum up, from the founding to the present, Nanjing Library reference service has witnessed the reference renaissance period (1950s), reference boom period (in the late 1970s to 1980s) and reference improving period (1990s) in China. Despite twists and turns and twists and turns, earth-shaking changes have taken place, it has developed into the best period of history.

\section{Legislative Decision-Making Information Service of Nanjing Library}

In 2000, Nanjing Library established a special information service group in the original reading department. In 2011, it officially changed its name to the legislative decision service group, which belongs to the Reader Service Department. In recent years, the Library makes full use of the collection of all kinds of literature and network resources, by means of directional and personalized service, gives full play to the decision-making reference, actively provide comprehensive information reference services for the communist party leadership of Jiangsu Province, key research institutions and enterprises. After more than 10 years of practice accumulation, the legislative decision-making information service not only enriches the connotation of reference service, but also greatly enhances the social influence and reputation of Nanjing Library.

\section{Compilation and Printing of Legislative Decision-Making Information Service Publications}

- Information Gathering (formerly known as Information Facsimile). Founded in 2001, is an important carrier for the legislative decision-making information service of Nanjing Library. It is secondary literature presents the hot spots information in the reform and opening up, such as politics, economy, culture and people's livelihood, and the main service object are the provincial, municipal party and government leadership and related cultural department leader. In order to further enhance the reference and readability of the publication, Nanjing Library actively adjusts the thinking of the magazine, and tries to report the social hot spots of different periods in various angles, depth and all aspects. As of now, there will be a total of 450 copies of the magazine in more than 500 periods. The magazine has been repeatedly praised by the provincial party committee, provincial government and relevant departments of the leadership, won the "outstanding service award of public libraries in Jiangsu Province" issued by the Provincial Cultural Department, named "excellent publications" by the Provincial Press and Publication Bureau. Information Gathering has been gradually established as the brand product of Nanjing Library's external information service. 
- The Study of Countermeasures. In 2012, in order to enhance the level of Nanjing Library legislation decision-making information service and strengthening legislation decisionmaking service function, while doing daily information service well Nanjing Library effectively integrated the famous experts and scholars research strength in the province at the same time, and set up more than 20 experts team, actively edited the special report The Study of Countermeasures for the provincial party committee, provincial government leadership, which has proactive, timeliness and operability features. No.1 was written by Nanjing Forestry University's professor and doctoral tutor Zhang Qisheng, who is the member of Chinese Academy of Engineering, titled "Research and Application of Biomass Gasification and Polygeneration Technology", which adopted by provincial leadership and refer to this article, Jiangsu Province People's Government introduced "On Promoting the Opinions of the Comprehensive Utilization of Crop Straw". No.2 was written by Zhang Jingxiang, a professor and doctoral tutor at Nanjing University, titled "Actively Innovating the Updating Mechanism for Land Use in the City Industrial Park", which was approved by vice governor Xu Ming and asked to transfer to the Provincial Department of Land for research. No.4 was written by Southeast University Professor and doctoral supervisor Ye Zhirui, titled "Strategy Research of Resolving the Problem of Provincial Highway Traffic Safety Administration", and approved by vice governor Shi Heping and asked to turn to Provincial Communications Department for inquiry and reading. This work is another important step for Nanjing Library to implement the legislative decision-making information service function.

- Nanjing Library's Trends. In September 2012, Nanjing library began to compile Nanjing Library's Trends, which includes: the latest guidance from leaders at all levels, Nanjing Library's recent work measures, rules and regulations and dynamic work, etc. So far, a total of 16 volumes of the publication have been edited.

- Consideration for Reference, Hong Kong and Taiwan Newspaper Digest. In order to promote the academic research results to the transformation of laws, regulations and policy of Jiangsu Province, Nanjing Library strengthens the contact with the Provincial People's Congress, Provincial Political Consultative Conference. According to the Jiangsu People's Congress standing committee issues issued about once every two months. The Library chooses one or two hot issues, compiles Consideration for Reference to provide the basis for our Provincial People's Congress on the legislation and the reference. At the same time, it actively uses the collection database to print the Hong Kong and Taiwan Newspaper Digest the internal reference for the main leadership of the Provincial People's Congress and the provincial people's political consultative conference, which are very popular with them. The work also makes Nanjing Library's annual "Two Sessions" on-site service transform into the annual normal and daily service for the Provincial People's Congress and the Provincial Political Consultative Conference.

\section{Providing On-site Information Service for the Provincial "Two Sessions"}

Starting from 2010, Nanjing Library has eight years in a row into the Provincial "Two Sessions" headquarters, to take the oral consultation service and the way of the combination of Internet counseling, for the people's congress, the Provincial Political Consultative Conference member provided free of charge all forms of literature information consulting services, public opinion monitoring, etc. Service contents are supplying free Nanjing Library card, issuing Information Facsimile, Leadership, The Books Recommend etc., searching answer questions related to bill, supplying electronic books, newspaper and magazine borrowing (download) and legislative decision-making information service platform to scan, providing remote digital access to resources, etc. Over the past eight years, nearly 800 cards have been issued for representatives 
and members, and more than 10000 references materials are issued. Nearly 7,000 people have been consulted.

\section{Building a Network Information Service Platform}

In 2012, Nanjing Library website added Jiangsu legislation decision-making information service platform, which not only links to the Nanjing Library outsourcing and self-built resources, also set up the "Two Sessions' Concern", "Legislation Tendency", "Government Management", "Cultural Overview", "Yangtze River Delta Economy", "Development in Jiangsu Province", "Universal Windows" and other eight real-time update programs, letting the Provincial People's Congress deputies and the Provincial Political Consultative Conference members who usually never leave home can enjoy Nanjing Library quick and comprehensive information and special information service about the "Two Sessions". In 2011, Nanjing Library actively participated in the "national provincial public library decision-making consultation service collaboration platform resource construction work" led by the National Library of China, and become one of the first eight members. In the process, the Library shared with other first members the legislation decision-making information service experience, services, products and achievements of characteristic digital resources construction, so as to improve the level of Nanjing Library's legislation decision-making information service.

\section{Providing Topical Information and Direct Public Opinion Monitoring Services}

Since 2004, Nanjing Library is designated as the information straight points of provincial party committee general office, general office of the provincial government, provincial people's congress and provincial party committee propaganda department. According to the various leadership department's information demand, the Library's legislation decision-making information service group submitted the relevant work experience in government, National People's Congress information reference, early warning information, public opinion, Hong Kong, Macao and Taiwan hot spot information, macroeconomic project information for four departments' monitor regularly, including multiple reporting information adopted by each leadership department for reference, and got the leaders' affirmation at all levels. Their information materials about the development of Jiangsu Province, the social and livelihood of Jiangsu Province and the development of coastal development in Jiangsu Province have supported the website construction of the Provincial Academy of Social Sciences. The Library assisted the Provincial Cultural Department in the public opinion monitoring work of the office directly affiliated to the Department, edited the Public Opinion Monitoring, and timely and effectively resolved the public opinion crisis. Information for all kinds of projects and public opinion monitoring service not only widens the scope of legislation decision-making information service, but also gave full play to the role of providing information services by provincial public library for the party and government organs' legislation decision-making reference.

\section{Nanjing Library Reference Service Tomorrow}

Nanjing library establishes the overall goals in their career development "Thirteen-Five" plan, which are centering on strategic objectives of "stepping a new level, constructing new Jiangsu", promoting the work, trying to make the Library become the important base of information resources, become an important window of benefiting people service, become an important platform for cultural exchanges, so as to achieve "domestic first-class, internationally advanced" at the end of "Thirteen-Five". In determining its seventh largest task "perfect consulting decisions service", it makes clear "improve reference service" "perfect the legislation decision-making service" and "advance science and technology novelty searching work" and other specific requirements. It is predicted that Nanjing Library reference service in the next 3-5 years will be presented the development trend of the following aspects: 


\section{The Level of Domestic and Foreign Joint Reference Consultation and Inter-library Loan Service Will Be Further Improved}

As Nanjing Library has had more than 40 ten thousand collection data of Chinese books published after 2007 uploaded to the OCLC WorldCat, the next step it will continue to upload the collection of features literature. Consulting number, the demand of international interlibrary loan and document delivery proposed from countries around the world by OCLC WorldShare platform, domestic readers' demand of consulting, borrowing foreign library collection literature will rise. Nanjing Library will continue to take an active part in coconstruction and sharing of "The Promotion of the Digital Library Project: The National Network of Library Reference Work" "Yangtze River Delta Network". With the help of the Project at the same time, The Library will continue to push forward with systems such as the National Library of China, Shanghai Library, JALIS cooperation to construct "Jiangsu Borrowing Each Other's Network", and have the "Public Library Reference Network in Jiangsu Province" covered the entire province various counties and districts, get through the "last one kilometer" of information reference services.

\section{The Level of Legislative Decision-making Service for Party and Government Organs Will Be Further Improved}

Nanjing Library will continue to attend the construction and maintenance of the "National Public Library Legislation Decision-making Collaboration Platform", further improve the compiling level of Information Gathering, Consideration for Reference, Hong Kong and Taiwan Newspaper Digest, The Countermeasure Research, The Hong Kong and Taiwan News, publications such as, strengthen their effectiveness and pertinence, give full play to the role of legislative decision-making consultation service. The Library will continue to serve the information services of the provincial "Two Sessions", build and manage the Nanjing Library branch of The Provincial People's Congress, lead and promote the similar services of libraries in the provinces and regions. At the same time, it will directly participate and actively complete the project of Jiangsu Monograph on Bibliography presided over by The Government, The Provincial Party Committee Propaganda Department of Jiangsu Province, Xu Xiaoyue curator as chief expert, and directly participate and actively complete the major cultural project of Cultural Context and the Research in Jiangsu Province and participate in the unit to complete The Bibliography as the main research task.

\section{The Service Level of Science and Education Research Enterprises, Production Enterprises and National Innovation Strategies Will Be Further Improved}

Nanjing Library has fostered a number of sci-tech novelty retrieval team and 3 Sci-Tech novelty auditors who have passed national qualification of the Sci-Tech novelty searching. Introduction and installation of The Database Dialog International Online Retrieval work has been implemented. According to a new state science and technology novelty search standard, it has set up The Nanjing Library Science and Technology Novelty Search Center, with this hand to better the implementation of the strategy for national innovation drive and the scientific research and production enterprises and institutions services.

\section{The Application Level of New Media Technology Will Be Further Improved}

Emerging of new social media such as Weibo, WeChat, APP and mobile services client, changed the way information retrieval, transfer and preservation, and profoundly influenced the speed, breadth and depth of information needs of social masses. To satisfy the public demand, further get social acceptance and recognition, Nanjing Library will increase the use of new media technology to provide the magnitude of the reference service on the basis of opening Weibo, WeChat, APP services, intensify propaganda promotion of their own marketing in the service of readers. 
Looking back, the history of Nanjing Library reference service went through twists and turns, there have been setbacks, but the devotion, consummate business and achievements of our predecessors still let people sigh unceasingly and make us proud! With pride and hope we have more in the future, and confident. Along with our country's powerful pace of building moderately prosperous society, Nanjing Library reference service will go to the new stage and to the new brilliance in her second one hundred.

\section{References}

Cai S. (1935) Learning and Libraries. The Eighth Annual of Jiangsu Provincial Library of Chinese Studies.

Chen L. (2016) The Chinese Ancient Culture Studies Library of Nanjing Library is Formally Open: An Ancient Books Reading Area Unique among Libraries. Available at: http://www.jslib.org.cn/njlib_gqsb/201610/t20161012_149096.htm.

Chen L. (2016) "Jiangsu Context Collation and the Research" Receives Additional Funding from National Social Science Foundation. Available at: http://www.jslib.org.cn/njlib_gqsb/201606/t20160614_146946.htm.

Jiang F. (1978) Zhen Zhou Ji, Volume II: Books and Library, Book One, Taipei: Taiwan's Commercial Press. Jiangsu Provincial Department of Culture and Nanjing Library. (2012) Public Libraries in Jiangsu Province Records, Nanjing: Jiangsu People's Publishing House.

Li F. (2012) Textual Research on Origin of the Reference Work of Libraries in China and Related Issues. Theoretical Research of Library Science.

Li X. (1982) Ancient Chinese Books and Modern Library Materials, Beijing: China Book Bureau.

Liu D. (1980) The Introduction of Liu Yizheng. Journal of Nanjing Normal University (Social Science Division).

Nanjing Library. (2006) Nanjing Library (1996-2005), Nanjing: Nanjing Press.

Nanjing Library. (2016) Brief Introduction to Nanjing Library, Nanjing: Nanjing Library.

Records of Nanjing Library Editorial Group. (1996) Nanjing Library (1907-1995), Nanjing: Nanjing University Press.

Wang B and Tang X. (2012) The Development of the Network of Collaborative Digital Reference Service in Jiangsu Province: Taking the Joint Reference Network of Public Library of Jiangsu Province as an Example. 2012 ChinaASEAN Cultural Forum: Asian Libraries: Resource Sharing, Cooperation and Development. Nanning.

Wang Q. (2014) Compilation of Modern Library Historical Materials, Nanjing: Phoenix Press.

Wang Y. (1991) Development history of Chinese Library, Changchun: Jilin Education Press.

Xie Z. (2005) China Book and Library History, Wuhan: Wuhan University Press.

Xu J and Xu S. (1996) Collected Works of Chen Qingnian, Haikou: Nanhai Publishing Company.

Xu S. (1995) Chen Qingnian and Jiangnan Library. Journal of Jiangsu Library.

Yan W. (1983) Development History of Library in China: From the End of Qing Dynasty to Anti-Japanese War, Hsinchu: Maple City Press.

Yang B and Han D. (1985) Chinese and Municipal Libraries in China (1919-1949), Beijing: Bibliography Press.

Yang T. (2016) Nanjing Library Holds a Ceremony for Tao Style Signing and for the Launch of Gentle Breeze Book Hall. Available at: http://www.jslib.org.cn/njlib_gqsb/201604/t20160427_144962.htm.

Zeng R. (2016) Nanjing Library Opens Its Children's Library for 0-6 Years Old to the Public: First Time of Nanjing Library, Leading within the Nation, Realizing the Full Coverage of Entrance Age. Available at: http://www.jslib.org.cn/njlib_gqsb/201610/t20161012_149098.htm.

Zhan D. (2000) 20th Century Chinese Reference Services: Development History, Achievements and Limitations. University Library Work.

Zhang J. (1984) Literature Review of Chinese Library, Taipei: Taiwan Student Bookstore.

Zhang K and Ji G. (1992) A History of Changes in Jiangnan Library. Journal of Jiangsu Library. 